\title{
Formation of the identity of the profitable complexes of the Old Tatar Quarter in Kazan of the late XIX - Early XX centuries
}

Dilyara Nadyrova ${ }^{1 *[0000-0003-4804-6481]}$

${ }^{1}$ Kazan State University of Architecture and Engineering, 420043, Zelenaya st., Kazan, Russia

\begin{abstract}
The article is devoted to the study of the formation of the architectural identity of the profitable complexes of the turn of the XIX and XX centuries of the Old Tatar Quarter - one of the oldest ethnic districts of Kazan. Profitable buildings and complexes of the studied period constitute a significant part of the preserved development of this territory. The article reveals the little-studied facts of the formation of profitable houses, examines the nature of their functional content, establishes the relationship between the material and non-material components of identity. Comprehensive analysis of the materials revealed the multifunctional nature of the profitable complexes. The level of identity of the complex is determined by the variety of its material and non-material features. A special role in the formation of the identity of the complex was played by the intangible component, which was determined by various factors. The results of the research are important for the restoration of cultural heritage sites and the introduction of little-known and unpublished archival materials into scientific circulation. Determining the identity of the profitable buildings of the Old Tatar Quarter is important for the further sustainable development of the district and for the preservation of the culture of the Tatar people.
\end{abstract}

Keywords: profitable house, identity, history of architecture, Old Tatar Quarter, historic centre.

\section{Introduction}

\subsection{Multifunctional profitable complex}

The objects of this research are multifunctional profitable complexes of the Old Tatar Quarter of Kazan, formed and functioning until the end of the 1910s. The multifunctional profitable complex included buildings combined into a common volumetric-spatial structure within the boundaries of one private household and rented out for different functions. A profitable house could be included in such a complex as an object with one function or a residential building with an extended range of functions. The Old Tatar Quarter in Kazan was a specific zone formed in the middle of the 16th century on the shore

\footnotetext{
* Corresponding author: Dilyaran@yandex.ru
} 
of Kaban Lake and intended for resettlement mainly of the Tatar population. By the end of the 19th century, the southern part of Zabulachye with Sennaya Square and the market were included in the Old Tatar Quarter. Already in the second half of the 19th century, wealthy Tatar families bought houses in this promising area in terms of entrepreneurship and income with the intention of further construction and leasing out buildings for residential rooms and commercial real estate.

The planning and development of the Old Tatar Quarter have been thoroughly investigated in the historical and architectural aspect in the works of the architectural historians G.N. Aydarova, R.S. Aydarov, G.N. Nugmanova, N.Kh. Khalitov [1-4].

The relevance of the stated topic lies in the fact that currently the profitable complexes of the late 19th - early 20th centuries are the most common type of development in the historical and architectural environment of the Old Tatar Quarter and Kazan. Currently, a theory of sustainable urban development has emerged, where sustainability is understood as a process aimed at finding a balance in preserving heritage and the possibility of new construction. Researches in the aspect of identity theory conducted in a number of European and Asian countries confirm the importance of the existence and development of architectural identity [5-8]. Architecture, which has its own identity, reveals the ideas, thoughts and perceptions of people who lived in a particular period of time; if the architectural identity is lost, then this can lead to the loss of identity and instability in the country [9]. In addition, discovery of the identity of profitable complexes will contribute to their scientifically grounded preservation and use in modern conditions and in the future.

\subsection{Identity of architectural objects}

The architectural identity of an object is defined as a historically formed set of its material and non-material features and is revealed by means of identifiers (codes) of identity, that is, the basic characteristics of the object. The theoretical aspects of the identity of the historical and architectural environment and its components are the subject of research by foreign and Russian researchers: G. V. Esaulov [10], T. V. Vavilonskaya [11], A. A. Skalkin [12], A. G. Bolshakov, N. M. Glebova [13] and others [14-16]. In foreign studies, great importance is afforded to the national-ethnic code, which characterizes identity most vividly [17-18].

According to the originality of the displayed identifiers, architectural identity can be unique, specific, typical (according to T. V. Vavilonskaya). N. M. Glebova and A. G. Bolshakov distinguish two different forms of «architectural identity». The first form includes objects that represent a symbol of the era, which are accents or peculiar landmarks in the general urban development. They can symbolize a certain time period, a significant historical event. The second form is observed in ordinary urban development during the formation of history and local traditions. It has a massive character, widespread in a particular city [19]. Both of these forms, in fact, represent unique and typical types of identity. A specific kind of identity takes an intermediate position.

Researchers distinguish the following identification codes that characterize the architectural identity of objects: urban planning, ethnic (national), architectural and historical, functional, event-related, mental $[5,11,15]$. 


\section{Materials and methods}

The research methodology of the profitable complexes of the Old Tatar Quarter of Kazan is based on bibliographic, archival and field studies and methods of comparative, contrastive and graphical analysis. To study the revenue complexes of the Old Tatar Quarter, the author conducted a full-scale survey of them (visual inspection, detailed photographs). Analysis of bibliographic materials and archival documents stored in the funds of the National Archives of the Republic of Tatarstan made it possible to identify the lost profitable complexes «Caravan-sarai» hotel and the Apanaevs' profitable complex on Parizhskaya Komunna street). Using the method of analytical sampling, several objects have been selected that meet the criteria of complexity, profitability, historical significance, expressiveness of appearance, etc.: profitable complexes of S. Z. Usmanov at the intersection of Moskovskaya and Fuksovskaya streets (Moskovskaya street, 53/G. Kamala street, 6); of Yunusovs on Moskovskaya street (Moskovskaya street, 66); of Apakov - Shamil - Galeev at the intersection of Moskovskaya and Sennaya streets (Parizhskaya Komunna street, 10/Moskovskaya, 72); of Apanaev brothers on Sennaya street (Parizhskaya Kommuna street) (object is lost); of Apanaev on Evangelistovskaya street (Tatarstan street, 8); of Sh. Shamsutdinov on Tikhvinskaya street («House of Shakir-Soldier») (Gabdulla Tukay street, 16); «Bulgar Rooms» at the intersection of Moskovskaya street and Evangelistovskaya street (Moskovskaya street and Tatarstan street) (object is lost); "Carava-nsarai» of Galeevs and Utyamyshevs on Sennaya street (Parizhskaya Kommuna street) (object is lost); «Amur Rooms» on Moskovskaya street (Moskovskaya street, 70); «Apanaevskoe podvorie» on Moskovskaya street (since 1910 it is «Moscovskie Rooms») (Moskovskaya street, 60) (Fig. $1)$.
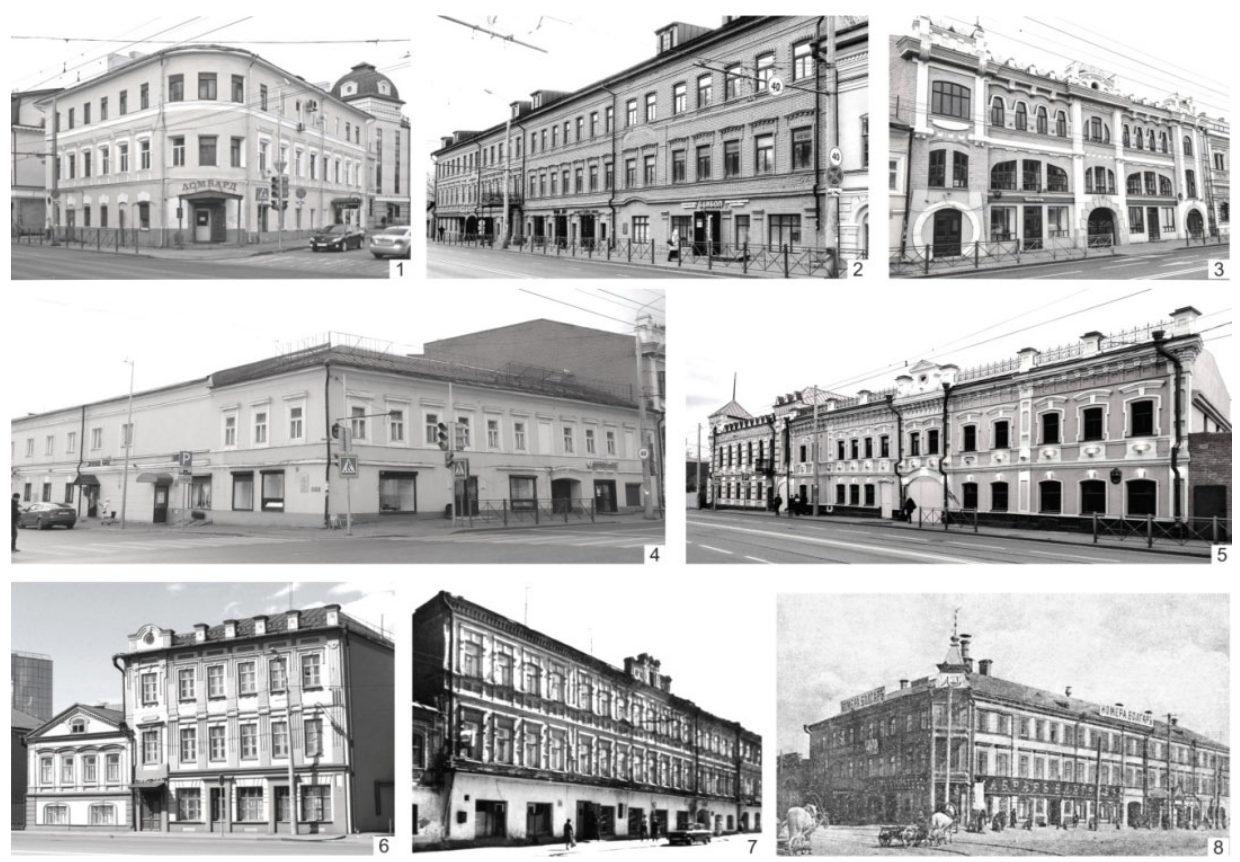

Fig. 1. 1. S.Z. Usmanov's profitable house, 2. «Apanaevskoe podvorie» (since 1910, as «Moskovskie Rooms »), 3 «Amur Rooms», 4. Profitable house of Apakov - Shamil - Galeev, 5. Profitable house of Sh. Shamsutdinov («House of Shakir-Soldier»), 6. Apanaev's profitable house - photos of the author; 7. The profitable house of the Galeevs and Utyamyshevs - «Carava-nsarai» (the object is lost). Photo by V. Glazov (https://pastvu.com), 8. «Bulgar Rooms». Postcard of the early 20 th century (the object is lost). 
All selected objects were analyzed according to the following parameters:

- the history of the formation and development of the complex in the period under review, confirmed by archival or bibliographic materials;

- spatial-compositional and space-planning structure of the complex and its relationship with the functional content of its objects;

- space-planning and architectural-stylistic structures of the main objects of the complex and their relationship with the commercial component of the functional content of their premises.

\subsection{Research of profitable complexes of the Old Tatar Quarter}

The research was conducted taking into account the task of identifying and forming the identity of revenue complexes, for which the main characteristics (identification codes) of architectural objects (according to T.V. Vavilonskaya) were studied: urban planning, architectural-historical, functional, national-ethnic, event-related. The author summarizes the results of the research based on the individually considered characteristics of each object:

- Urban planning identifier. All the former profitable complexes under consideration are located on a flat relief, in the area of Sennaya Square of the Old Tatar Quarter, which was the center of the commercial and business life of the Tatar population. Some of them, for example, «Amur Rooms», "Apanaevskoe Podvorie», «House of Shakir-Soldier» were located in a closed row of residential buildings, others at the intersection of streets, occupying the corner part of the blocks - profitable complexes of S. Z. Usmanov, Apakov Shamil - Galeev, «Bulgar Rooms». Connection with the courtyard space of the complexes in most cases was carried out through the passage tunnel on the first floor of the street building - «Amur Rooms», «Caravan-serai», «Apanaevskoe Podvorie», «Bulgar Rooms», the Usmanovs' revenue complex. In the Apanaevs' revenue complex on Evangelistovskaya street the entrance to the territory was through the gate.

- Architectural and historical identifier. The formation of profitable complexes of households dates back to the middle of the 19th century. The earliest are the Apakov Shamil - Galeev profitable complex at the intersection of Sennaya and Moscovskaya streets. The history of the construction of the main house here began in 1833, and in 1859 it was rebuilt according to the project of P. T. Zhukovsky. It is this building, to the part of which later the second floor was added, that we can observe today (Fig. 2).

a. Spatial-compositional structure of the complexes. The spatial organization of profitable complexes was determined by the historical parceling at the end of the 19th beginning of the 20th centuries. Some of the households retained their borders from the moment of formation until 1917, while some expanded over the years due to the joining of neighboring plots to them. The latter include profitable complexes: «Apanaevskoe Podvorie», «House of Shakir-Soldier», Bulgar Rooms. The spatial compositional structure of the complexes can be divided into three types. The first one is households, arranged according to the principle of a complete perimeter-closed space: revenue complexes of S. Z. Usmanov, «Caravan-serai», «Amur Rooms». Second is the households with buildings located at a distance from each other along the perimeter of the site, thus forming an open courtyard: «Bulgar Rooms», «House of Shakir-Soldier». The third type, when additional buildings have been located in the center of the courtyard: «Apanaevskoe Podvorie».

b. Space-planning structure of the complexes was formed by an inner courtyard, around which there were residential, office and utility buildings. Household and office buildings, which included baths, stables (later garages), woodsheds, hayloft, were usually one-, twostorey, and residential buildings were two- and three-storey. Many buildings were reconstructed over several decades, building on or adding new parts of the buildings until 
the plots turned into large revenue complexes: «Apanaevskoe Podvorie», «Bulgar Rooms», «Amur Rooms».

c. Space-planning and architectural-stylistic structures of buildings and structures of profitable complexes. The planning solutions of the main parts of the buildings were mostly of the corridor type with one-sided or two-sided location of rooms, hall type or combined. The facades of the considered revenue houses of the Old Tatar Quarter, judging by the historical photographs, were originally unplastered: red brick or painted. Such were the «Bulgar Rooms», profitable house of Apakov - Shamil - Galeev, the main facades of which were later partially or completely plastered. By the design of the facades, two types of style trends can be distinguished: eclecticism with elements of classicism or oriental motives and modern. Among all the revenue houses it is worth noting the «Amur Rooms», which stand out for their modern facade (1912) among the other buildings on Sennaya Square, and the «House of Shakir-Soldier», made in the style of the medieval Arab East. Courtyard buildings of all profitable complexes were practically devoid of decor, plastered or retaining the brick texture of the main parts of the buildings of the complex.

Some of the profitable houses received their completed appearance after various reconstructions, which included: the additional upper floor with the preservation of the general style of the facade (the Galeev and Utyamyshev's profitable house - «Caravanserai» (Fig. 3); the profitable house of Apakov -Shamil - Galeev); the additional upper floor with a change in the appearance of the house «Amur Rooms» [20]; the inclusion of previously existing buildings in the new volume and their unification into one facade («Apanaevskoe Podvorie», in which the street facade of the main building is made of red unplastered bricks in the eclectic style and retained elements of the classic architecture of the previous buildings; "House of Shakir-Soldier»); an extension of a new volume to the existing one («Bulgar Rooms», the profitable house of Apanaev brothers on Sennaya street, «House of Shakir-Soldier»). The new construction includes the Yunusovs' profitable house on Moskovskaya street and the Apanaevs' profitable house on Tatarstan street.

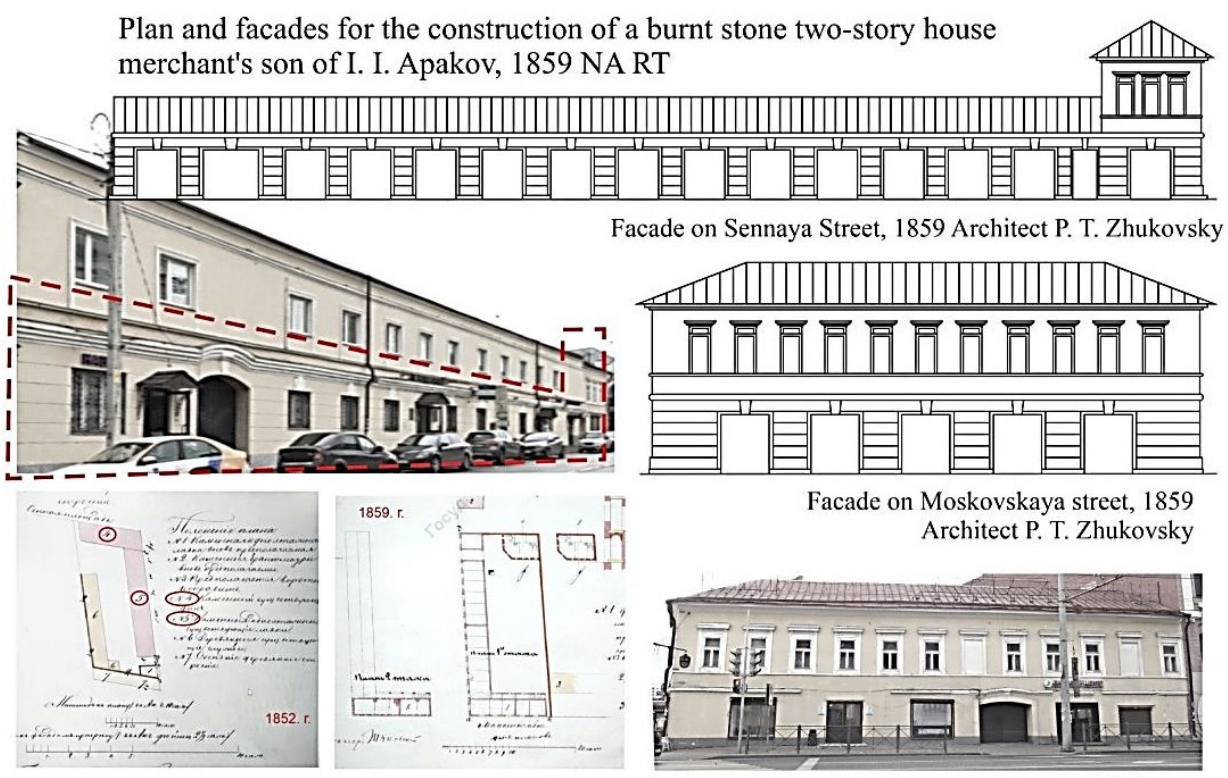

General plan of the site of the honorary 1st guild of the merchant son of Ibragim Iskhakov Apakova 1859, NA RT

Fig. 2. Profitable house of Apakov - Shamil - Galeev. Facades of the house from the project of 1859. Architect P. T. Zhukovsky and modern view of the house in 2020. Drawings and photos of the author. 


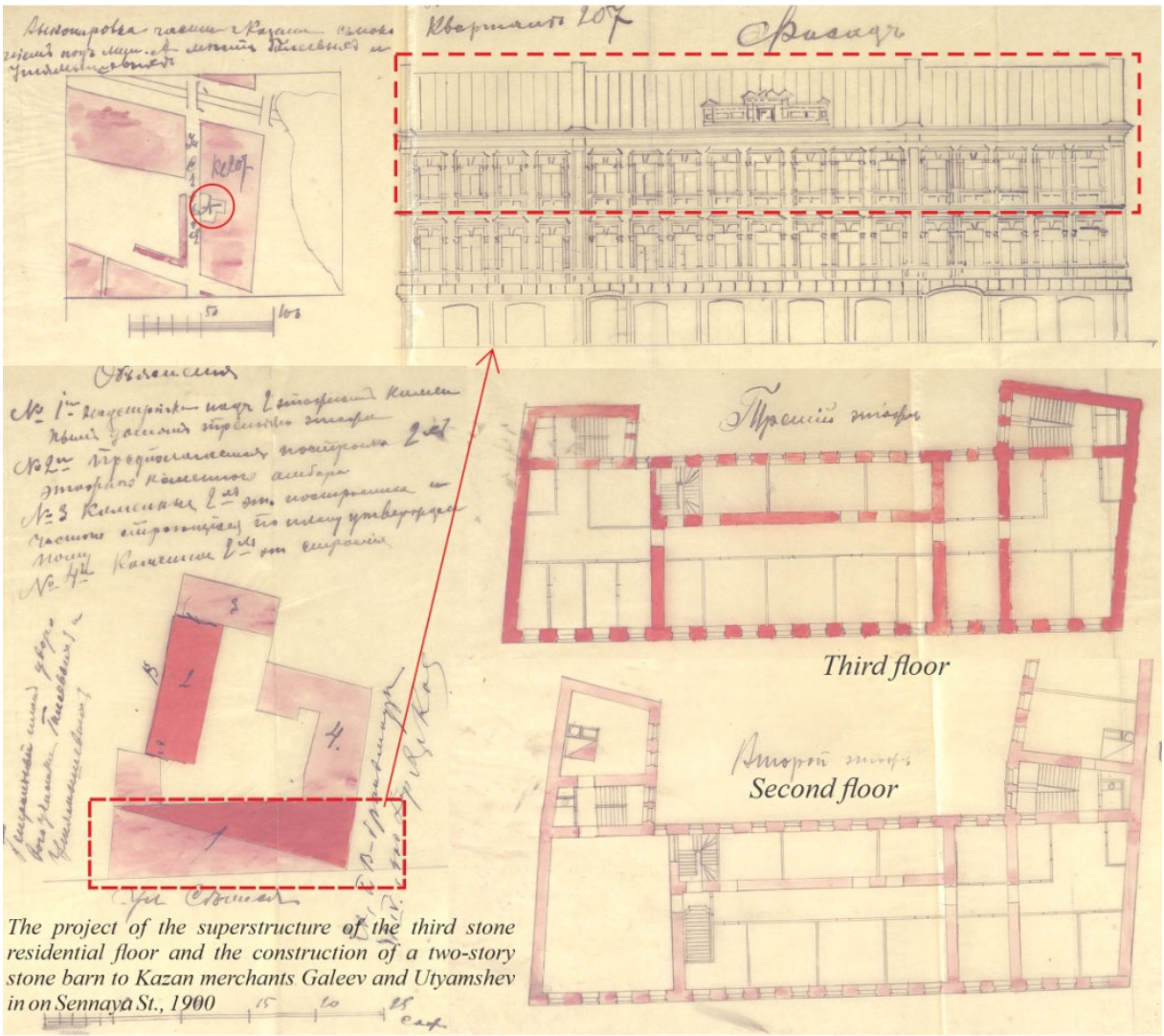

Fig. 3. The Galeev and Utyamyshev's profitable house - «Caravan-serai» The project of the superstructure of the third stone residential floor. National archive of the Republic of Tatarstan, F.98. Paper, ink, watercolor, 1900.

- Functional identifier. As a rule, on the first floors of the street bulk there were trade shops, and on the first floors of the courtyard buildings there were warehouses. Also, in the courtyard buildings were all the service premises that served the residential buildings of the complex. For example, in Usmanov's profitable complex, the first floors were occupied by shops selling raw leather and a bakery, and in the house of Apakov - Shamil - Galeev there was a leather trade shop, a haberdashery shop, in the profitable house of the Utyamyshevs Galeevs («Caravan-serai») - a soap shop «Partnership of Apanaev and Burnaev».

The residential function included apartments and rooms for rent or arrangement of rooms and hotels: Koroleva's Rooms were located in the Usmanovs' profitable complex; in the profitable house of the Galeevs and Utyamyshevs - «Caravan-serai» Hotel; in the Yunusovs' profitable complex - «Amur Rooms»; in the Anaevs' complex - «Apanaevskoe Podvorie» Hotel; in the House of Sh. Shamsutdinov - apartments for rent, etc. Apartments and hotels, as a rule, were located on the 2 nd and 3rd floors of the main building of the complex and in additional residential courtyard buildings.

Administrative premises could be located on the first and on the upper floors: the newspaper office of the «Koyash» newspaper was located in the Yunusovs' revenue complex; editorial offices of the newspapers «Vostochny Club», «Reforma», publishing house «Magarif», printing house were located in the revenue house of Apakov-KhuainovKazakov («Bulgar Rooms»). 
The entertainment and leisure function of the profitable complexes of the Old Tatar Quarter was most vividly represented by the «Vostochny Club», in the Bulgar Rooms in 1907. Later it moved to the profitable complex of the Apanaevs on Evangelistovskaya street, where there was an auditorium for 150 people, a library.

Also in the considered objects could be located premises of public catering, medical direction (doctor's office, etc.), educational (library), production and service. The considered profitable complexes included several of the above functions. Thus, the functional identifier shows the commercial and residential, industrial and warehouse, entertainment and educational nature of the revenue complexes, which confirms their multifunctional nature.

- National and ethnic identifier. Since the profitable complexes were located in the Old Tatar Quarter, the main residents of revenue houses were the Tatar population. However, the placement of objects in the immediate vicinity of the trading square - Sennoy Bazar, near the Tikhvin and Evangelical Churches caused the residence of representatives of the Russian and other peoples of the region. That is, the profitable complexes were designed for living and using its various premises by representatives of all nationalities of the region.

- Mental identifier was determined by the predominance of representatives of the merchant class, the bourgeoisie, the peasantry who came to the market with goods, burghers, peasants who came to the market with goods, artisan workers in the Sennaya Square area. The considered revenue complexes for the most part belonged to Tatar merchants and industrialists - Apanaevs, Apakovs, Galeevs, Utyamyshevs, Usmanovs, Yunusovs. They, as a rule, built large three-storey houses, intended for rooms, with additional residential and office buildings in the courtyards: - «Apanaevskoe Podvorie», «Caravan-serai», «Amur Rooms». In addition, there was another type of profitable house, the appearance of which looked like an ordinary merchant's estate, and services, storerooms, baths formed an economic courtyard, which was typical for a Tatar town mansion of the $19^{\text {th }}$ - early 20 th centuries. These include the House of Shakir-Soldier, which belonged to the Sh. Shamsutdinov [21].

-Event-related identifier is associated with an important urban development center of Kazan, which was the Sennoy Bazar. By the beginning of the 20th century, Sennaya Square was no longer just a trade center of the Old Tatar Quarter, but also the center of the spiritual, social life of the Tatars, a place where national culture was concentrated. The editorial offices of Tatar newspapers, magazines, and printing houses were located in revenue houses. The first library of the national book was opened in the «Bulgar Rooms», here the Tatar intellectual class opened «Vostochny Club», for the development of the national theater, literature, music. G. Tukai, F. Amirkhan, G. Kamal, G. Kulakhmetov, G. Kariev and other prominent figures of Tatar culture performed in it. In 1911 - 1915, the first Tatar theater troupe «Sayyar» worked in the building. The profitable complexes of the Old Tatar Quarter are also closely related to the names of historical figures: the poet G. Tukai lived in the «Apanaevskoe Podvorie», "Amur Rooms», «Bulgar Rooms»; artist G. Kariev and writer F. Amirkhan stayed in the "Amur Rooms»; the revolutionaries Kh. Yamashev and M. Vakhitov lived in the «Apanaevskoe Podvorie», etc.

All considered revenue complexes were built by famous Tatar merchant families and dynasties. For example, the Apanaevs are one of the ancient and wealthy Tatar surnames of Kazan, which was inherited by merchants, entrepreneurs, landowners, public and religious figures, teachers and honorary citizens of the city, benefactors, trustees.

\section{Results}

It has been established that in the housing development of the Old Tatar Quarter of Kazan in the period under consideration there were objects of both typical and unique and specific 
identity. The group of objects with a specific identity can be attributed «Amur Rooms», the profitable complex of the Sh. Shamsutdinov. And such revenue complexes as: Yunusovs, Apanaevs on Sennaya street, «Apanaevskoe Podvorie», "Caravan-serai», «Bulgar Rooms», which are similar in space-planning and architectural-stylistic characteristics, can be attributed to objects with simple, i.e. typical identity. Objects with such an architectural identity were widespread in the development of cities in the Russian Empire in the late 19th and early 20th centuries. However, in this case we are talking about the material component of identity. Since some samples have a unique non-material (spiritual) component of identity - «Bulgar Rooms», a certain discrepancy between the material and non-material components of identity is revealed. It is necessary to adjust and take this into account when assessing a cultural heritage object and establishing its full identity.

It has been established that cultural heritage objects classified according to the material component to a group with a simple identity, according to the non-material component can be classified as groups with a specific or unique identity.

\section{Discussions}

The identifiers (identification codes) of the multifunctional profitable complexes of the Old Tatar Quarter of Kazan, revealed as a result of the research, are a manifestation of the identity of the historical and architectural environment of the city at the facility level. In these researches Vavilonskaya T. V., Kosenkova N. A., Serova A. A., Nadyrova Kh. G. studies of the historical and architectural environment of the city were carried out up to the level of the quarter. Kosenkova N. A. and Serova A. A. focused on public buildings [15]. In this case, there was a kind of «deepening» in the research of the historical and architectural environment of the city to the level of «home ownership - complex - architectural object». Such a research allows, through this level, to identify unknown features of the past (historical) identity of a given area of the city. Using this technique, other types of buildings can be studied in the future: religious, public, etc. On this basis, it will be possible to develop the modern identity of the Old Tatar Quarter and the city. And in the future, the interaction of historical and modern identity will ensure sustainability in the architectural and urban development of Kazan.

The results of the research, including the introduction of little-known and unpublished archival materials into scientific circulation, can be used for projects for the restoration of historical and cultural objects. Determining the role of profitable houses of the Old Tatar Quarter in the development of Kazan is significant for the further preservation, competent development and housing development of the area, for increasing the tourist attractiveness of the area and for the history of the culture of the Tatar people [22].

\section{Conclusion}

As a result of the study, it was established that:

1. Profitable complexes of the Old Tatar Quarter had a multifunctional character. In such complexes, the main ones were residential, commercial, warehouse, administrative, production functions, for which buildings and individual premises were rented out in various volumes and combinations.

2. The organization and development of the complexes proceeded by expanding the territory through the purchase and joining of neighboring households, by compacting the development of plots, increasing the number of floors in the volume of buildings. 
3. A characteristic feature of the style of the facades of the buildings of the investigated profitable complexes of the Old Tatar Quarter was brick eclecticism with classicist elements, when the facades were in red or painted brick.

4. The identity of profitable complexes of the Staro-Tatarskaya Sloboda is manifested by identifiers (identification codes Urban planning, architectural-historical, functional, national-ethnic, mental, event-related, etc. The level of identity of the complex was determined by the diversity and richness of identifiers. The non-material component (spirit of the place) of identity played a special role in the level of identity of the complex. It is determined by national-ethnic, mental, event-related identifiers, which are conditioned by historically important events and the names of people associated with revenue complexes. Often the non-material component prevails in the general characteristic of the identity of the complex, raising it from simple (typical) to the level of specific or unique.

The study and preservation of the identity of the profitable complexes of the Old Tatar Quarter will contribute to the sustainable development of this area of Kazan and the city as a whole. In the future, research in this area should be continued at the sites of the religious, estate, industrial architecture of the Old Tatar Quarter.

\section{References}

1. G. N. Aidarova-Volkova, Unknown mosques of the Old Tatar Quartert of the second half of the XVI - first half of the XVIII centuries, Historical ethnology, 4, 2, 219-234 (2019)

2. R. S. Aidarov, Wooden buildings of Kazan streets in the second half of the X1X-early XX centuries, Izvestija KGASU, 7 (8), (2007)

3. G. G. Nugmanova, Haymarket Square of Kazan: the history of building development. Tatar settlements of Kazan: Essays on History (Publishing House of the Institute of History of the Academy of Sciences of the Republic of Tatarstan, Kazan, 80-131, 2002)

4. N. H. Khalitov, N. N. Almenova-Halit, Styles and forms of Tatar architecture of Kazan in the second third of the XVIII-early XX centuries: historical and architectural research (Tatar Book Publishing House, Kazan, 391, 2014)

5. Kh. G. Nadyrova, The problem of reviving the identity of the architecture of the Old Tatar settlement of Kazan, Historical ethnology. Scientific Journal, 4, 2. 255-263 (2019)

6. R. Adam, Identity and Identification: The Role of Architectural Identity in a Globalised World. The Role of Place Identity in the Perception, Understanding, and Design of Built Environments, 176-193 (2012)

7. R. Gambassi, Identity of modern architecture in historical city environment, Architecture and Engineering, 1, 2, 27-42 (2016)

8. Kh. Truspekova, A. Galimzhanova, M. Glaudinova, National identity and architecture of Nur-Sultan, Humanities \& Social Sciences Reviews, 7, 5, 374-386 (2019)

9. Z. Torabi, S. Brahman, Effective Factors in Shaping the Identity of Architecture, Middle-East Journal of Scientific Research, 15(1), 106-113 (2013)

10. G. V. Esaulov, About identity in architecture and urban planning, Architecture, 4, 12 18 (2018)

11. T. V. Vavilonskaya, The concept of "Architectural and historical environment» and the criteria that define it, Traditions and innovations in construction and architecture, Urban planning, in Collection of articles of the 74th International Scientific and Technical conference, Samara, 187-192 (2017)

12. A. Skalkin, Architectural Identity of the City: Concept and Research Methods, Architecture and Modern Information Technologies, 2(43), 87-97 (2018) 
13. N. M. Glebova, A. G. Bolshakov, N. Narantuya, New forms of architectural identity on the shores of Lake Baikal, Izvestiya vuzov. Investment. Construction. Real estate, 3(26), 155-169 (2018)

14. A. V. Tsorik, L. P. Kholodova, A. V. Shvets, Architectural and artistic identity of cities, Questions of theory and history in urban planning, architecture and design, $\mathbf{1}$, New Ideas of the New Century, 351-360 (2016)

15. N. A. Kosenkova, A. A. Serova, Formation of the identity of public objects on the example of Samara, Urban planning and architecture, 8, 1, 109-116 (2018)

16. F. V. Perov, Influence of the morphology of the architecture of the historical city on the problems of identification of the urban environment, Architecture, urban planning and design, 6, 10-18 (2015)

17. M. Amiri, Z. Hasibi, Rehabilitation and Restoration of Identity-Oriented Values of Traditional Architecture Concepts in Current Architecture in Iran, Special Issue of Curr World Environ 2015, 10 (2015)

18. H. H Samir, Y. Arayici, The Influence of Modern Architecture in Transforming Iraqi City Identity (2015) URL: https://www.researchgate.net/publication/338558050 (last accessed 12.04.2021)

19. N. M. Glebova, A. G. Bolshakov, Principles of preservation and formation of architectural identity in the street construction of the historical part of Irkutsk, Izvestiya vuzov. Investment. Construction. Real estate, 9(3), 606-619 (2019)

20. L. Sh. Sayfullina, Yu. V. Vasilyeva, A. T. Khairullina, Rooms «Amur» in the building of the Haymarket square of the Old Tatar Quarter, The World of Art: Bulletin of the International Institute of Antiques, 1(01), 167-175 (2013)

21. L. Sh. Sayfullina, Usadba «Shakir-soldata», Mir iskusstva: Vestnik Mezhdunarodnogo instituta antikvariata, 2(02), 107-110 (2013)

22. A. I. Abdrakhmanova, R. R. Khairutdinov, The realities and prospects of the development of the Old Tatar settlement of Kazan as an object of tourist display, Kazan Bulletin of Young Scientists, 2(5), 5-8 (2018) 